\title{
Protection of DNA During Preparative Agarose Gel Electrophoresis Against Damage Induced by Ultraviolet Light
}

BioTechniques 21:898-903 (November 1996)

\author{
Dirk Gründemann and Edgar \\ Schömig \\ University of Heidelberg, \\ Heidelberg, Germany
}

\begin{abstract}
Preparative gel electrophoresis of double-stranded DNA usually includes staining the gel with ethidium bromide followed by illumination with ultraviolet $(U V-B)$ light. In this report, DNA isolated from agarose gels was found to be a poor substrate for in vitro transcription, transformation of $\mathrm{E}$. coli and PCR. Inhibition was not caused by enzyme-inhibiting impurities in the agarose gel, but was induced by a standard transilluminator fitted with 312-nm tubes. Interestingly, it was possible to protect the DNA against $U V$ damage by the addition of cytidine or guanosine to the electrophoresis buffer.
\end{abstract}

\section{INTRODUCTION}

Preparative agarose gel electrophoresis is a standard method to isolate double-stranded DNA fragments of defined sizes. After electrophoresis in a horizontal agarose gel and staining of the DNA with the fluorescent dye ethidium bromide, an agarose block containing the fragment of interest is cut out while the gel is illuminated with ultraviolet (UV) light. Subsequently, the DNA is isolated from the agarose block according to one of the numerous protocols that have been described in the past.

Unfortunately, difficulties in the manipulation of DNA thus isolated from agarose gels are common. For example, after ligation of isolated fragments into plasmid vectors, bacteria have been transformed with low efficiency. These difficulties are generally believed to result from remaining agarose impurities $(16,17)$.

This report documents an alternative cause for the inhibition of DNA processing. With three functional assays, we demonstrated that DNA in an agarose gel may suffer extensive damage by radiation from a standard UV transilluminator. To protect the DNA from this detriment, a simple and effective remedy has been devised that relies on the addition of guanosine or cytidine to the electrophoresis buffer.

\section{MATERIALS AND METHODS}

\section{Materials}

Nucleosides (BioChemika grade) were from Fluka (Neu-Ulm, Germany).
Agarose (15510-027 for the silica protocol; low-melting-point agarose 5517UB for the HTAB protocol) was from Life Technologies (Eggenstein, Germany). All other chemicals were of analytical grade.

A TF-20 M UV fluorescent table (Vilber-Lourmat, Marne-la-Vallée, France) was used, fitted with six 312nm tubes (T-15 M, $15 \mathrm{~W}$ each). Comparison was made with a TWM-20 Transilluminator (Ultraviolet Products, San Gabriel, CA, USA) housing four 312-nm lamps (No. 34004201) and a Transilluminator 4000 (Stratagene, Heidelberg, Germany) fitted with five 312-nm tubes (8 W each).

\section{General Methods}

Standard procedures and composition of TE, TAE and TBE buffers have been described (16). Nucleic acids were precipitated with ethanol in the presence of $10 \mu \mathrm{g}$ linear polyacrylamide as a carrier (4). Digital images of agarose gels were processed with Photoshop ${ }^{\mathrm{TM}}$ software (Adobe Systems, Mountain View, CA, USA). All data are given as mean \pm SEM, which were calculated from at least three independent evaluations for each condition.

\section{Preparative Agarose Gel Electrophoresis}

Agarose $(0.8 \%)$ was boiled in the respective electrophoresis buffer and cast to a height of $5 \mathrm{~mm}$. For in vitro transcription and electrotransformation, 1.0 $\mu \mathrm{g}$ per lane of plasmid pBlueOCT1, linearized with HindIII, was loaded onto the agarose gel. pBlueOCT1 (4.8 
$\mathrm{kb})$ is pBluescript ${ }^{\circledR}$ SK (-) (Stratagene) containing the cDNA of OCT1 (5). For polymerase chain reaction (PCR), a sample containing $140 \mathrm{ng}$ of a $1.85-\mathrm{kb}$ cDNA was loaded. Electrophoresis was performed for $1 \mathrm{~h}$ at a field strength of $5 \mathrm{~V} / \mathrm{cm}$ with constant recircularization of buffer from anode to cathode in a conventional submarine chamber (Mini-Sub ${ }^{\circledR}$ Cell; Bio-Rad, München, Germany). After staining for $10 \mathrm{~min}$ with $1 \mu \mathrm{g} / \mathrm{mL}$ ethidium bromide in electrophoresis buffer, the gel was placed on a UV table. The DNA was irradiated for $45 \mathrm{~s}$, during which an agarose block containing the DNA was cut out with a scalpel. Isolation from the gel block was performed using either the method of extraction with hexadecyltrimethylammonium bromide (HTAB protocol) (11) or the QIAquick $^{\mathrm{TM}}$ gel extraction kit (Qiagen, Hilden, Germany), which basically consists of dissolution of the gel with a chaotropic salt and binding of DNA to a silica matrix (silica protocol) (18). The recovered DNA was precipitated with ethanol and dissolved in TE buffer.

\section{In Vitro Transcription}

Linearized plasmid $(0.2 \mu \mathrm{g})$ was incubated $2 \mathrm{~h}$ at $37^{\circ} \mathrm{C}$ in $40 \mathrm{mM}$ triethanolamine- $\mathrm{HCl}, \mathrm{pH} 7.5\left(37^{\circ} \mathrm{C}\right), 1$ $\mathrm{mM}$ each of ATP, CTP, GTP and UTP, $10 \mathrm{mM} \mathrm{MgCl} 2,5 \mathrm{mM}$ dithiothreitol (DTT), $5 \mathrm{U} / \mathrm{mL}$ inorganic pyrophosphatase from yeast, $0.5 \mathrm{U} / \mu \mathrm{L}$ RNase inhibitor from human placenta and $40 \mathrm{U}$ T3 RNA polymerase in a final volume of $25 \mu \mathrm{L}$. After extraction with phenol and chloroform, and ethanol precipitation, one-half of the product was denatured with glyoxal in the presence of ethidium bromide and analyzed on a $1 \%$ agarose gel as described (6). For quantitation of full-length transcript synthesized with $40 \mu \mathrm{M}$ UTP plus 0.02 $\mu \mathrm{M}[\alpha-32 \mathrm{P}] \mathrm{UTP}(110 \mathrm{~Bq} / \mathrm{fmol}$; Amersham, Braunschweig, Germany), the gel was dried and analyzed by radioluminography with the BAS1000 system (Fuji Photo Film, Tokyo, Japan).

\section{Electrotransformation}

Linearized plasmid ( $35 \mathrm{ng}$ ) was incubated overnight at $16^{\circ} \mathrm{C}$ with $4 \mathrm{U} \mathrm{T} 4$

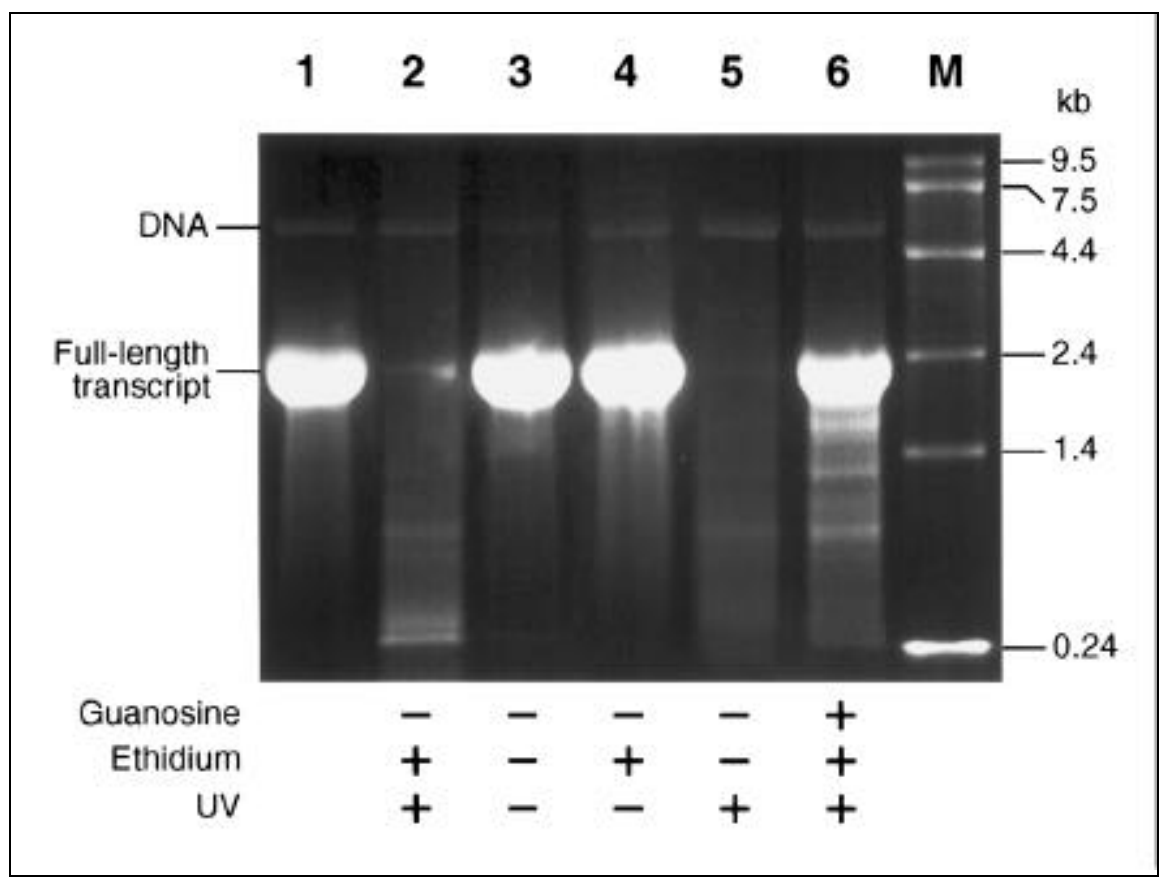

Figure 1. DNA quality after preparative agarose gel electrophoresis as assayed by in vitro transcription. Shown are the fluorescent, denatured products of in vitro transcription separated according to size by agarose gel electrophoresis. Except for the untreated control in lane 1, the template DNA was isolated from agarose gels as described in Materials and Methods using TAE as electrophoresis buffer and employing the silica protocol. As indicated, template DNA was prepared with or without $1 \mathrm{mmol} / \mathrm{L}$ guanosine in the electrophoresis buffer, ethidium bromide staining and UV irradiation. A total of $0.1 \mu \mathrm{g}$ 0.24-9.5-kb RNA ladder (Life Technologies) was applied to lane M.
DNA ligase in a volume of $10 \mu \mathrm{L}$ in the buffer supplied by the manufacturer (Fermentas, St. Leon-Rot, Germany). After extraction with phenol and chloroform and precipitation with ethanol, nucleic acids were resuspended in 20 $\mu \mathrm{L} 0.5 \times$ TE. DNA solution $(1 \mu \mathrm{L})$ was mixed with $20 \mu \mathrm{L}$ of electrocompetent E. coli $\mathrm{DH} 5 \alpha$ cells and subjected to electroporation as described (7). Ampicillin-resistant colonies were scored.

\section{PCR}

DNA recovered from agarose (10 pg) was amplified in 25 cycles ( $1 \mathrm{~min}$ $94^{\circ} \mathrm{C}, 2 \mathrm{~min} 59^{\circ} \mathrm{C}$ and $2 \mathrm{~min}$ at $72^{\circ} \mathrm{C}$ ) in the buffer provided (Promega, Madison, WI, USA) containing $0.2 \mathrm{mM}$ dNTPs, $2.3 \mathrm{mM} \mathrm{MgCl}$, $2.5 \mathrm{U}$ Taq DNA polymerase and two specific primers (33 and 27 bases long, respectively; $0.5 \mu \mathrm{M}$ each) in a final volume of $100 \mu \mathrm{L}$. For analysis, one-fifth of the product was loaded onto an agarose gel.

\section{RESULTS}

In pilot experiments, the quality of DNA was assessed by scoring colonies on agar plates after recircularization of linear plasmid DNA ( 2.7 or $4.8 \mathrm{~kb}$ ) with ligase and electroporation into $E$. coli bacteria. When the complete protocol of preparative agarose gel electrophoresis was followed, which consisted of electrophoresis, staining with ethidium bromide, cutting out an agarose block under UV illumination and isolation of the DNA from the block according to the HTAB protocol, the efficiency of transformation of the isolated DNA was reduced by 2 to 3 orders of magnitude as compared to control DNA. By contrast, the efficiency of transformation was not decreased when the DNA was isolated according to the HTAB protocol from TAE buffer, with or without the addition of an empty agarose block, cut from a gel after electrophoresis (data not shown). It was concluded that damage or contamination of DNA had occurred during electrophoresis or during staining with ethidium bromide followed by UV illumination.

To differentiate between these steps, two identical samples of plasmid pBlueOCT1 linearized with HindIII were 
subjected to electrophoresis on the same agarose gel. Subsequently, the gel was cut between the two lanes. One sample was stained with ethidium bromide and cut out under UV illumination, while the other was cut out under room light with the stained gel half as a marker. After isolation of the DNA from the agarose blocks according to the silica protocol, in vitro transcription with $\mathrm{T} 3$ RNA polymerase was performed. The amount of full-length transcript, estimated by gel electrophoresis, was expected to reflect the intactness of the isolated DNA. From the DNA isolated in the conventional manner, hardly any fulllength RNA could be transcribed (Figure 1, lane 2). By contrast, DNA that had been subjected to identical electrophoretic and isolation procedures, but that had not been exposed to ethidium bromide and UV irradiation, was as good a template as untreated control DNA (cf. lanes 1 and 3). Staining with ethidium bromide alone did not affect the intactness of the DNA (lane 4). In fact, staining with ethidium bromide had a small protective effect against UV irradiation (cf. lanes 2 and 5).

The above results were not caused by a peculiarity of our fluorescent UV table, since similar damage of DNA was also observed with two other transilluminators from different manufacturers, designed for maximum output at $312 \mathrm{~nm}$ (data not shown).

Interestingly, when the nucleoside guanosine was added to the electrophoresis buffer at a final concentration of 1 $\mathrm{mmol} / \mathrm{L}$, good protection against the DNA damage induced by subsequent UV irradiation was observed (Figure 1, lane 6). Quantitation by use of $[\alpha-$ 32P]UTP and radioluminography revealed an increase in yield of fulllength transcript by a factor of about

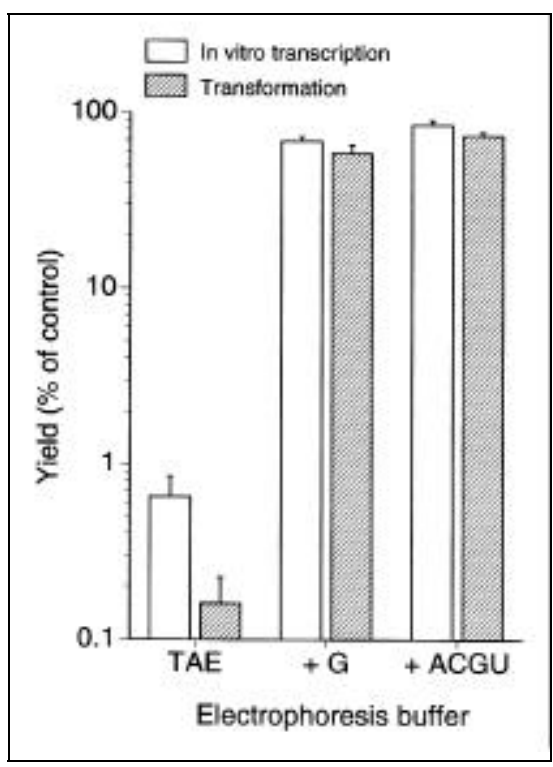

Figure 2. Effect of addition of nucleosides to the electrophoresis buffer on the efficiency of in vitro transcription and transformation. $\mathrm{Ag}$ arose gel electrophoresis of DNA was performed with TAE buffer (TAE) with or without the addition of adenosine (A), cytidine (C), guanosine (G) and uridine (U), each at $1 \mathrm{mmol} / \mathrm{L}$, as indicated. DNA was then isolated from the agarose gels employing ethidium bromide staining, UV irradiation and the silica protocol. To assess the efficiency of in vitro transcription of the isolated DNA, radiolabeled, full-length transcript was quantified as described in Materials and Methods (open bars). Transformation efficiency (hatched bars) was estimated from the number of $E$. coli colonies obtained after recircularization and electroporation of the DNA as described in Materials and Methods. Control DNA yielded (1.8 \pm $0.3) \times 10^{7}$ colonies per $\mu \mathrm{g}$.
100, compared with DNA separated conventionally in TAE buffer (Figure 2, open bars). The simultaneous presence of guanosine, adenosine, cytidine and uridine in the electrophoresis buffer, each at a concentration of $1 \mathrm{mmol} / \mathrm{L}$, had only a small additional protective effect vs. guanosine alone.

Analogous results were obtained when the various DNA preparations were recircularized with DNA ligase and electroporated into $E$. coli to determine the efficiency of transformation (Figure 2, hatched bars). Here, the addition of guanosine to the electrophoresis buffer increased the yield of clones by a factor of about 400, compared with conventionally prepared, unprotected DNA. Thus, according to both assays, more than $99 \%$ of the DNA was damaged after standard preparative agarose gel electrophoresis. By contrast, when the electrophoresis buffer contained guanosine, about two-thirds of the DNA remained fully functional.

The protection against UV damage provided by guanosine could also be demonstrated in PCR experiments

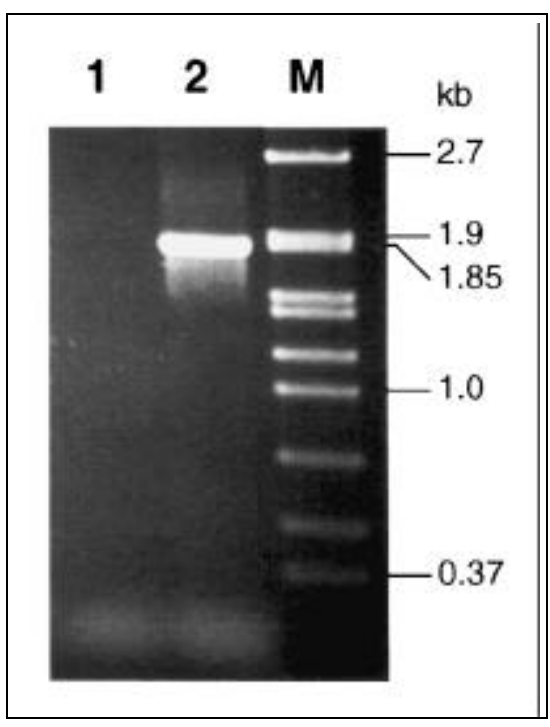

Figure 3. Effect of addition of guanosine to the electrophoresis buffer on the efficiency of PCR. Agarose gel electrophoresis of DNA was performed with TAE buffer (lane 1) or with TAE buffer containing $1 \mathrm{mmol} / \mathrm{L}$ guanosine (lane 2). DNA was then isolated from the agarose gels as described in the legend to Figure 2. PCR was performed with the isolated DNA as described in Materials and Methods, and products were analyzed by agarose gel electrophoresis. A total of 250 ng DNA marker VII (Boehringer Mannheim, Mannheim, Germany) was applied to lane M. The expected product size was $1.85 \mathrm{~kb}$. 
(Figure 3). PCR with DNA isolated in the conventional manner from an agarose gel was not successful (lane 1). However, when the electrophoresis buffer contained $1 \mathrm{mmol} / \mathrm{L}$ guanosine, an identical amount of isolated DNA was amplified with good yield (lane 2).

In supplementary in vitro transcription assays, guanosine in the electrophoresis buffer also protected against UV irradiation when either $0.5 \times$ TBE or the HTAB protocol of extraction was used. Phosphate $(1 \mathrm{mmol} / \mathrm{L})$ or DTT (5 $\mathrm{mmol} / \mathrm{L}$ ) instead of guanosine provided no protection. Figure 4 shows the yield of full-length transcript as a function of guanosine concentration. It is apparent that a concentration of $1 \mathrm{mmol} / \mathrm{L}$ is necessary to achieve substantial protection. Addition of $1 \mathrm{mmol} / \mathrm{L}$ guanosine to the ethidium bromide staining solution, was, at least with our staining protocol, without protective effect (data

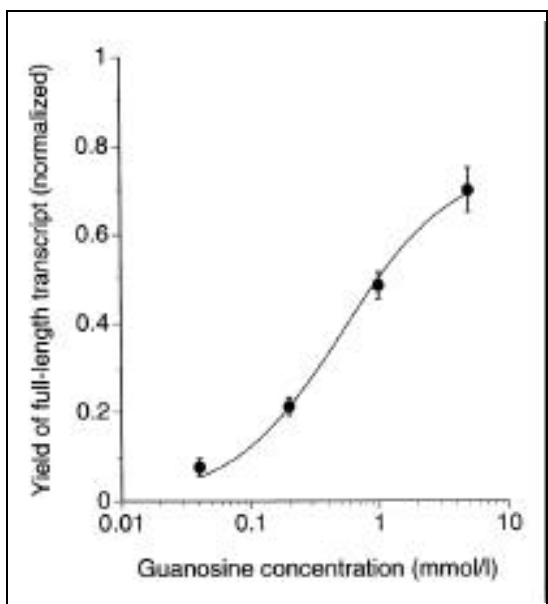

Figure 4. Protective effect as a function of guanosine concentration. Agarose gel electrophoresis of DNA was performed with TAE buffer in the presence of guanosine as indicated. DNA was then isolated from the agarose gels and assayed for the yield of radiolabeled, full-length transcript as described in the legend to Figure 2. Data were normalized by subtraction of the yield obtained with unprotected DNA, followed by division by the yield obtained with control DNA. The curve shown resulted from non-linear regression analysis. The parameters of a simple binding model, $\mathrm{Y}=\mathrm{P} \times \mathrm{C} /(\mathrm{K}+\mathrm{C})$, were fitted to the data. This model describes the normalized yield $(\mathrm{Y})$ as a function of guanosine concentration $(\mathrm{C})$, a dissociation constant $(\mathrm{K})$ and the maximum protection $(\mathrm{P})$. Values of 0.53 (95\% confidence interval: $0.37,0.74) \mathrm{mmol} / \mathrm{L}$ and $77(68,85) \%$ were obtained for $\mathrm{K}$ and $\mathrm{P}$, respectively. Note, however, that the data are almost equally well described by a simple cooperative model that implies a maximum protection of $100 \%$. not shown). Interestingly enough, while adenosine and uridine could not replace guanosine, cytidine was as effective as guanosine in protecting DNA against UV-induced damage (Figure 5).

Finally, it should be noted that, in a side-by-side comparison, incorporation of guanosine into the agarose gel was without any apparent effect on the fluorescence intensities of ethidium bromide-stained DNA bands (data not shown).

\section{DISCUSSION}

Preparative agarose gel electrophoresis of DNA may be hampered by the presence of enzyme-inhibiting impurities in the agarose $(16,17)$. In the past, this has led to the development of various isolation procedures $(9,16,17)$ and prompted many investigators with demanding applications to fractionate their DNA using methods like gel filtration or density gradient centrifugation, which provide poorer resolution $(10,14)$.

In our experience, DNA prepared from agarose was often a poor substrate, especially in processes that require the DNA to be copied in its whole length, such as transformation (which includes replication), in vitro transcription and PCR. However, from experiments described in this work, it was

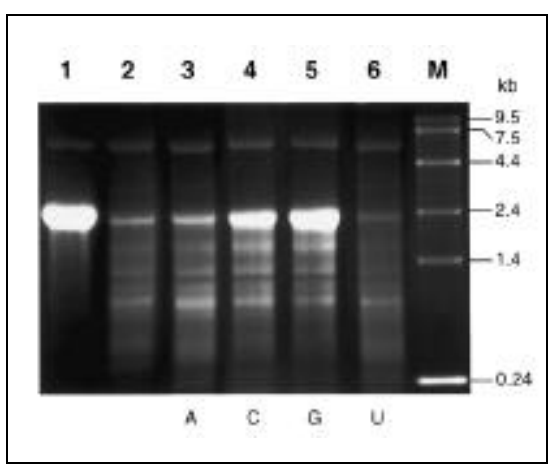

Figure 5. Protective effects of the individual nucleosides as assayed by in vitro transcription. Agarose gel electrophoresis of DNA was performed with TAE buffer (lane 2) or with TAE buffer containing $1 \mathrm{mmol} / \mathrm{L}$ of the indicated nucleoside (abbreviated as in the legend to Figure 2) (lanes 3-6). DNA was then isolated from the agarose gels as described in the legend to Figure 2 and examined by in vitro transcription as described in the legend to Figure 1. For lane 1, untreated control DNA was used. 
concluded that neither isolation from the agarose block, ethidium bromide staining nor electrophoresis had a detrimental effect on the quality of the DNA. Instead, it was shown that inefficient processing of DNA was solely due to illumination with UV light.

It is well known that UV light damages DNA. Alterations such as pyrimidine dimer formation, base destructions, breakage of sugar phosphate chains and interstrand DNA-DNA crosslinks have been reported (see Reference 15 for a review). However, from current protocols for the fluorescent detection of ethidium-DNA complexes after gel electrophoresis, the impression emerges that UV-induced DNA damage is usually of minor importance (2). With a standard UV transilluminator fitted with UV-B tubes, only insignificant damage is assumed to accumulate in a period of minutes (13).
It was therefore quite surprising to learn from our functional assays that, even in the short period of time (20 to $45 \mathrm{~s}$ ) that is needed to cut out a single band, DNA in an agarose gel may suffer extensive damage on a standard UV table. Our data from the in vitro transcription assay and from the coupled assay of ligation and transformation of E. coli demonstrate that less than $1 \%$ of the DNA remained intact. In PCR experiments, the damage prevented amplification of isolated DNA.

In line with our results, it has been reported previously that transillumination of gels can damage DNA and compromise subsequent manipulations $(3,8,13)$. Unfortunately, the experimental conditions were different from those actually used in preparative agarose gel electrophoresis. Also, it was not possible to relate the significance of UV damage to other steps in preparative gel electrophoresis.

Clearly, the ultimate solution to this problem is to avoid UV irradiation altogether. However, this is inconvenient and may often be impractical. Using weaker UV sources, with the disadvantage of reduced sensitivity, helps to alleviate, but does not abolish, the damage. UV-B sources (peak intensities around $300 \mathrm{~nm}$ ) are considered as the most appropriate UV source, since, compared with 254-nm sources, they have been shown to provide lower risks of photodamage and photobleaching and, compared with 366-nm sources, they offer higher sensitivity (2).

As an alternative, a remedy was found that requires little change to the conventional protocol of preparative DNA electrophoresis and no modification or replacement of existing UV tables. The presence of cytidine or guanosine in agarose gels had a strong, albeit not absolute, protective effect on DNA against UV irradiation. Protection was concentration-dependent and specific, in that adenosine and uridine were ineffective. Judging from Figure 2 , combinations of nucleosides do not seem to result in additional benefit. When choosing between cytidine and guanosine, which appear to be equally effective, it should be considered that cytidine dissolves faster and to higher concentrations, and guanosine is cheaper by a factor of about 3 on a molar ba- sis. It is important to note that the nucleosides do not impede electrophoresis, detection or purification of DNA. Compared with the use of 366nm UV sources to reduce damage to DNA (8), inclusion of cytidine or guanosine in the gel is superior, in that fluorescence intensities are not affected.

The nature of the damage that blocks T3 RNA polymerase, Taq polymerase and possibly a DNA polymerase from $E$. coli active in plasmid replication, and the molecular mechanism of protection provided by cytidine and guanosine, are presently uncertain. Given the similar absorption coefficients of the nucleosides at $260 \mathrm{~nm}$, it seems unlikely that protection is affected by absorption of UV light before it reaches the DNA. Anyhow, it is generally accepted that formation of dimers between adjacent bases constitutes the most prevalent photoreaction in DNA (1), and dimerization is assumed to be highly dependent on local DNA duplex motility $(1,12)$. Possibly, then, guanosine or cytidine protects against UV-induced damage by a specific interaction that modifies local DNA geometry or internal motions. In favor of this view, it has been demonstrated that DNA triplex formation, resulting from the addition of oligonucleotides to duplex DNA, prevents UV-induced formation of pyrimidine dimers (12).

In this report, a potentially severe pitfall in preparative agarose gel electrophoresis has been documented. With three different functional assays, it was shown that common UV tables may induce massive damage to DNA. In the future, the addition of cytidine or guanosine to the electrophoresis buffer should help to avoid this detriment.

\section{ACKNOWLEDGMENTS}

This work was supported by Deutsche Forschungsgemeinschaft (SFB 176). We thank Anke Ripperger for skillful technical assistance.

\section{REFERENCES}

1.Becker, M.M. and Z. Wang. 1989. Origin of ultraviolet damage in DNA. J. Mol. Biol. 210:429-438.

2.Brunk, C.F. and L. Simpson. 1977. Compar- 
ison of various ultraviolet sources for fluorescent detection of ethidium bromide-DNA complexes in polyacrylamide gels. Anal. Biochem. 82:455-462.

3.Cariello, N.F., P. Keohavong, B.J.S. Sanderson and W.G. Thilly. 1988. DNA damage produced by ethidium bromide staining and exposure to ultraviolet light. Nucleic Acids Res. 16:4157.

4.Gaillard, C. and F. Strauss. 1990. Ethanol precipitation of DNA with linear polyacrylamide as carrier. Nucleic Acids Res. 18:378.

5.Gründemann, D., V. Gorboulev, S. Gambaryan, M. Veyhl and H. Koepsell. 1994. Drug excretion mediated by a new prototype of polyspecific transporter. Nature 372:549-552.

6.Gründemann, D. and H. Koepsell. 1994. Ethidium bromide staining during denaturation with glyoxal for sensitive detection of RNA in agarose gel electrophoresis. Anal. Biochem. 216:459-461.

7.Hanahan, D., J. Jessee and F.R. Bloom. 1991. Plasmid transformation of Escherichia coli and other bacteria, p. 63-113. In J.H. Miller (Ed.), Methods in Enzymology, Vol. 204: Bacterial Genetic Systems. Academic Press, San Diego.

8.Hartman, P.S. 1991. Transillumination can profoundly reduce transformation frequen- cies. BioTechniques 11:747-748.

9.Hengen, P.N. 1994. Recovering DNA from agarose gels. Trends Biochem. Sci. 19:388389.

10.Kieffer, B.L. 1991. Optimised cDNA size selection and cloning procedure for the construction of representative plasmid cDNA libraries. Gene 109:115-119.

11.Langridge, J., P. Langridge and P.L. Bergquist. 1980. Extraction of nucleic acids from agarose gels. Anal. Biochem. 103:264-271.

12.Lyamichev, V.I., M.D. Frank-Kamenetskii and V.N. Soyfer. 1990. Protection against UV-induced pyrimidine dimerization in DNA by triplex formation. Nature 344:568-570.

13.Mäueler, W., A. Kyas, F. Bröcker and J.T. Epplen. 1994. Altered electrophoretic behavior of DNA due to short-time UV-B irradiation. Electrophoresis 15:1499-1505.

14.Murphy, A.J.M. and R.T. Schimke. 1991. plambdaZd39: a new type of cDNA expression vector for low background, high efficiency directional cloning. Nucleic Acids Res. 19:3403-3408

15.Nikogosyan, D.N. 1990. Two-quantum UV photochemistry of nucleic acids: comparison with conventional low intensity UV photochemistry and radiation chemistry. Int. J. Radiat. Biol. 57:233-299.
16.Sambrook, J., E.F. Fritsch and T. Maniatis. 1989. Molecular Cloning: A Laboratory Manual, 2nd ed. Cold Spring Harbor Laboratory Press, Cold Spring Harbor, NY.

17.Smith, H.O. 1980. Recovery of DNA from gels, p. 371-380. In L. Grossman and K. Moldave (Eds.), Methods in Enzymology Vol. 65: Nucleic Acids, Part 1. Academic Press, New York.

18.Vogelstein, B. and D. Gillespie. 1979. Preparative and analytical purification of DNA from agarose. Proc. Natl. Acad. Sci. USA 76:615-619.

Received 29 January 1996; accepted 22 April 1996.

\section{Address correspondence to:}

Dirk Gründemann

Department of Pharmacology

University of Heidelberg

Im Neuenheimer Feld 366

69120 Heidelberg, Germany

Internet: dirk.gruendemann@urz.

uni-heidelberg.de 